9 - ORIGINAL ARTICLE

ISCHEMIA-REPERFUSION

\title{
Influence of chlorpromazine on renal histology of rats submitted to ischemia and reperfusion injury ${ }^{1}$
}

\author{
Júlio César FoiattoI, Nicolau Gregori Czeczko", Eduardo Gabriel Guerber Wietzikoski', Osvaldo Malafaia" ${ }^{\text {II }}$ Thadeu Brenny \\ Filho $^{\text {III }}$, André Matos de Oliveira ${ }^{I V}$, Regina de Paula Xavier Gomes ${ }^{\text {V }}$ \\ DOI: http://dx.doi.org/10.1590/S0102-865020160110000009 \\ IFellow Master degree, Postgraduate Program in Surgery Principles, Medical Research Institute, Faculdade Evangélica do Paraná (FEPAR), Curitiba- \\ PR, Brazil. Conception, design, intellectual and scientific content of the study, manuscript preparation.

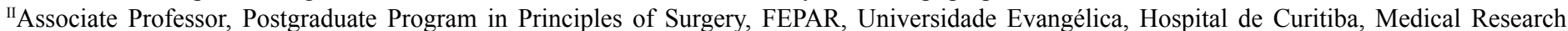 \\ Institute, Curitiba-PR, Brazil. Intellectual and scientific content of the study, interpretation of data, critical revision. \\ "IIMaster, Urology Department, Hospital São Vicente, Curitiba-PR, Brazil. Manuscript preparation.

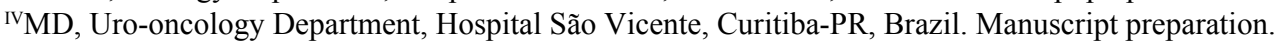 \\ ${ }^{v} \mathrm{PhD}$, Pathology Department, Universidade Federal do Paraná (UFPR), Curitiba-PR, Brazil. Histopathological examinations.
}

\section{ABSTRACT}

PURPOSE: To analyze the influence of chlorpromazine on renal histology of rats submitted to ischemia and reperfusion injury.

METHODS: Sixteen Wistar rats - split in two groups - have been used: control group, receiving $3 \mathrm{mg} / \mathrm{kg}$ isotonic saline solution through caudal vein, and, the chlorpromazine group, receiving $3 \mathrm{mg} / \mathrm{kg}-\mathrm{IV}$ of such medication. The nephrectomy of the left kidney lower third was carried out; immediately, the test-drug was administrated. After 15 minutes of test-drug administration, the renal pedicle was clamped; in 60 minutes of ischemia it was released. After 24 hours of the renal reperfusion, the rats were, once more, anesthetized and submitted to total left nephrectomy, and, afterwards, to euthanasia. Histological findings regarding ischemia have been evaluated and compared between the groups.

RESULTS: There was no statistical difference related to inferior renal pole histological analysis. Regarding 60-minute renal ischemia, chlorpromazine has statistically reduced the accrual of leucocytes within the vasa recta renis $(\mathrm{p}=0.036)$ and the congestion of peritubular capillaries $(\mathrm{p}=0.041)$. When conducting joint analysis of histological patterns, the control group showed a median score of 11 and chlorpromazine group of $5.5(\mathrm{p}=0.036)$.

CONCLUSION: Chlorpromazine significantly reduced the occurrence of secondary damage to ischemia and reperfusion process in the overall histological analysis.

Key words: Chlorpromazine. Nephrectomy. Renal Circulation. Reperfusion Injury. Rats. 


\section{Introduction}

In order to make renal transplants feasible, renovascular procedures, in some cases of renal lithiasis and nephron-sparing surgery, kidney ischemia must be produced; however, lesions due to ischemic and reperfusion procedures surmount more than $50 \%$ of acute renal insufficiency cases ${ }^{1}$. The greater the complexity of the small renal tumors, the greater the duration of ischemia required to excise $i^{2}$.

The kidney has low tolerance to ischemia; human solitary kidneys afford no more than 20 minutes on cold ischemia and no more than 35 minutes on warm ischemia ${ }^{3}$. Ischemia reversibility hinges on three variables: histology after reperfusion, ATP regeneration capabilities, and the ability to keep intracellular calcium homeostasis ${ }^{4,5}$.

Assessing the causes of acute renal failure secondary to acute tubular necrosis, postoperative ischemic factor emerges as the main cause and is related to greater severity and mortality ${ }^{6}$. Some pharmacological interventions can improve the clinical conditions in surgical procedures involving the phenomenon of ischemia and reperfusion, and, among the pharmacological preconditioning options, there is chlorpromazine. This drug is a phenothiazine with anesthetic properties, adrenolytic effect and action on the $\mathrm{Na}^{+}$/ $\mathrm{K}^{+}$-ATPase. The use of chlorpromazine had protective effect on the occurrence of renal failure in kidney transplant and tests that induced ischemia to kidney ${ }^{7-9}$.

The purpose of this analysis is to examine the influence of chlorpromazine on renal histology of rats submitted to ischemia and reperfusion injury.

\section{Methods}

This study occurred within the premises of Medical Research Institute, Faculdade Evangélica do Paraná (FEPAR). It had been approved by the Ethics Commission on Animal Use, FEPAR, under approval number 6953/2014.

The sample was based on 16 three-month old Wistar male rats (Rattus novergicus albinus, Rodentia mammalia), weighting $322.5 \pm 5.6 \mathrm{~g}$. They had been split in two groups and the test solution was administrated through caudal vein by $3 \mathrm{mg} / \mathrm{kg}$ :

- Control group - $\mathrm{CG}(\mathrm{n}=8)$ : ischemia with isotonic saline solution.

- Chlorpromazine group - CPZ $(n=8)$ : ischemia with chlorpromazine (Longactil ${ }^{\circledR}$, Cristália) (Figure 1).

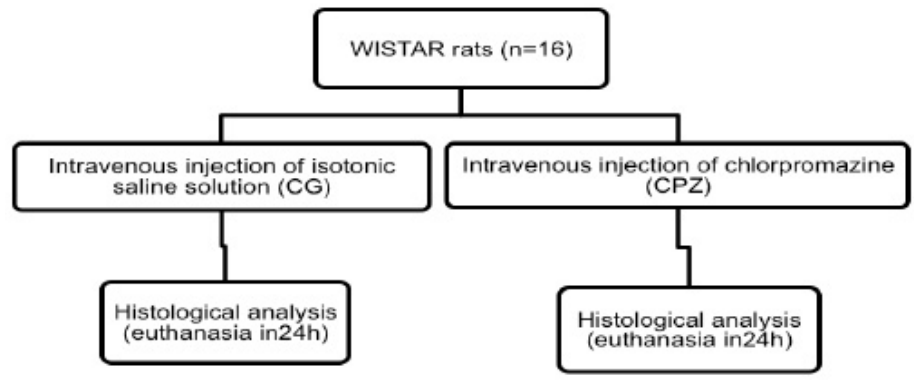

FIGURE 1 - Experimental protocol flowchart.

\section{Surgical procedure}

The animals were anesthetized with xylazine $2 \%, 10 \mathrm{mg} /$ $\mathrm{kg}$, (Dorcipec ${ }^{\circledR}$, Vallée) and ketamine 10\%, $90 \mathrm{mg} / \mathrm{kg}$, (Cetamin ${ }^{\circledR}$, Syntec) injected intraperitoneally and submitted to midline laparotomy towards identification and isolation of left kidney.

Such procedure occurred as follows:

- Zero: resection of left kidney lower third with scalpel - which set the histological standard previous to ischemia, and hemostasis review of resected renal bed with electrocautery;

- 2 minutes after resection of left kidney lower third: test solution infusion (chlorpromazine or isotonic saline solution);

- 15 minutes after test-drug administration: renal blood flow occlusion by vascular microclamp (Aesculap ${ }^{\circledR}$ ), including both renal vein and renal artery;

- 60 minutes of renal blood flow oclusion: left kidney reperfusion through microclamp removal, followed by hemostasis review and suture of abdominal wall;

- 24 hours after de main procedure: total left nephrectomy and animal euthanasia by anaesthetics overdose (Figure 2). 


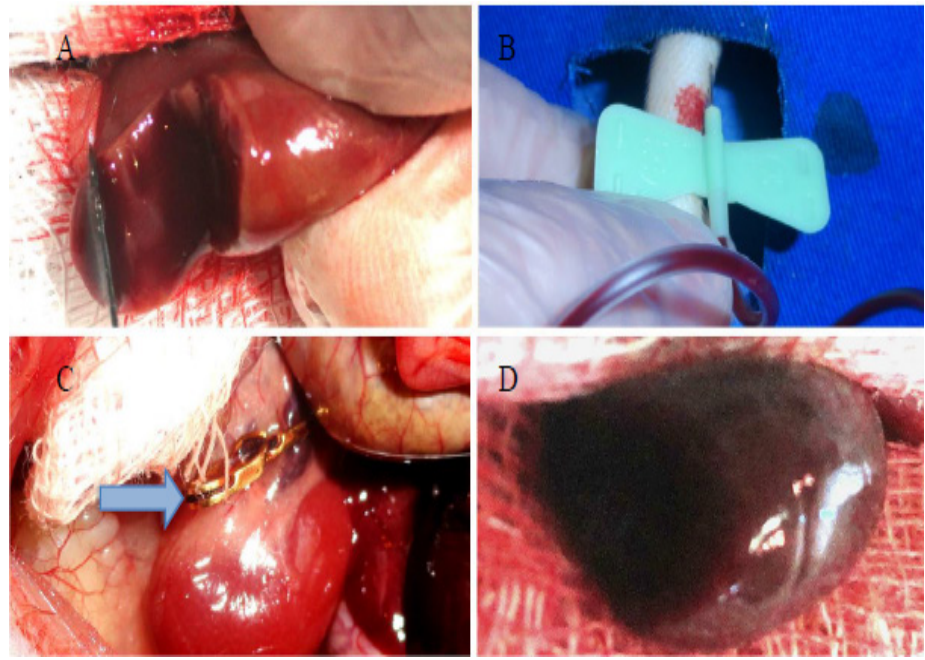

FIGURE 2 - Experimental process steps: (a) resection of left kidney lower third with scalpel; (b) injection of test substance (chlorpromazine or isotonic saline solution) through caudal vein; (c) vascular microclamp, including both left renal vein and renal artery (blue arrow); (d) left kidney under 60-minute warm ischemia

\section{Histopathology analysis}

The left kidney was dissected and sectioned transversely close to its hilum and each unit fixed in $10 \%$ formalin buffered. Then, there was routine histological processing. The parts were cut with a microtome in transerval axis and stained with hematoxylin and eosin.

Evaluated histological criteria:

1. Epithelial cell detachment from basement membrane,

2. Cell sloughing within the tubule lumen,

3. Flattening and loss of brush borders in the proximal tubules,

4. Tubular cylinders,

5. Interstitial edema,

6. Peritubular accumulation of leukocytes in the interstitium,

7. Peritubular capillary congestion,

8. Leukocyte accumulation in vasa recta renis,

9. Hydropic degeneration,

10. Dilation of the tubular lumen,
11. Cell necrosis,

12. Collapse of capillary tuft.

Each of the aforementioned criteria has received an individual score regarding the intensity of findings (Table 1).

\begin{tabular}{cc}
$\begin{array}{c}\text { TABLE } \\
\text { classifications }{ }^{10}\end{array}$ & - Ischemia histological analysis \\
\hline Classification & Histopathology standart \\
\hline 0 & Normal \\
0,5 & Small damage within focal areas \\
1 & $<10 \%$ damage in cortical area \\
2 & 10 to $25 \%$ damage in cortical area \\
3 & 25 to $75 \%$ damage in cortical area \\
4 & $>75 \%$ damage in cortical area \\
\hline
\end{tabular}

The slides were evaluated and reviewed by the same pathologist that was not blinded.

Histological variables have been analysed within MannWhitney nonparametric test using SPSS 13 (SPSS ${ }^{\circledR}$ Inc; Illinois, USA). Values of p lower than 0.05 indicated statistical significance.

\section{Results}

Histological findings on inferior renal pole were peritubular capillary congestion, hydropic degeneration and interstitial edema that occurred in $25 \%$ of the sample, and without statistical significance.

The histopathology findings determined by 60 -minutes ischemia which were present in all cases have been: tubular cylinders, hydropic degeneration, and peritubular capillary congestion. The observation of statistical significance in item peritubular capillary congestion was due to stratification of degrees of renal injury; in this regard, were more severe in the control group.

Table 2 shows the statistical analysis of the histological patterns studied. 
TABLE 2 - Median score and interquartile range (IQR) of histological injury determined by ischemia in groups control (CG) and chlorpromazine (CPZ).

\begin{tabular}{|c|c|c|c|c|c|}
\hline \multirow{2}{*}{$\begin{array}{l}\text { Histological } \\
\text { criteria }\end{array}$} & \multicolumn{2}{|c|}{$\mathbf{C G}$} & \multicolumn{2}{|c|}{ CPZ } & \multirow[t]{2}{*}{ p-value } \\
\hline & Median & IQR & Median & IQR & \\
\hline Tubular cylinders & 1.50 & 1.25 & 1 & 0.25 & 0.345 \\
\hline $\begin{array}{c}\text { Hydropic } \\
\text { degeneration }\end{array}$ & 0.75 & 0.75 & 0 & 1 & 0.115 \\
\hline $\begin{array}{l}\text { Peritubular capil- } \\
\text { lary congestion }\end{array}$ & 2 & 0.25 & 1 & 1 & 0.041 \\
\hline $\begin{array}{l}\text { Dilation of the } \\
\text { tubular lumen }\end{array}$ & 1 & 0.12 & 0.5 & 0.5 & 0.227 \\
\hline $\begin{array}{c}\text { Flattening and loss } \\
\text { of brush borders } \\
\text { in the proximal } \\
\text { tubules }\end{array}$ & 0.75 & 0.62 & 0.25 & 0.5 & 0.156 \\
\hline $\begin{array}{c}\text { Epithelial cell } \\
\text { detachment from } \\
\text { basement } \\
\text { membrane }\end{array}$ & 0.75 & 2 & 0 & 0.5 & 0.172 \\
\hline Interstitial edema & 0.5 & 0.5 & 0 & 0.5 & 0.318 \\
\hline $\begin{array}{l}\text { Cell sloughing } \\
\text { within the tubule } \\
\text { lumen }\end{array}$ & 0.5 & 0.5 & 0 & 0.12 & 0.270 \\
\hline $\begin{array}{c}\text { Leukocyte } \\
\text { accumulation in } \\
\text { vasa recta renis }\end{array}$ & 0.75 & 1 & 0 & 0 & 0.036 \\
\hline Cell necrosis & 0.5 & 2 & 0 & 0.12 & 0.227 \\
\hline $\begin{array}{l}\text { Peritubular } \\
\text { accumulation of } \\
\text { leukocytes in the } \\
\text { interstitium }\end{array}$ & 0 & 0.5 & 0 & 0 & 0.208 \\
\hline $\begin{array}{l}\text { Collapse of } \\
\text { capillary tuft }\end{array}$ & 0 & 1 & 0 & 0 & 0.401 \\
\hline
\end{tabular}

Among evaluated items, chlorpromazine has been able to significantly decrease congestion of peritubular capillaries and leukocyte accumulation in vasa recta renis, as in accordance with Figures 3 and 4, respectively.

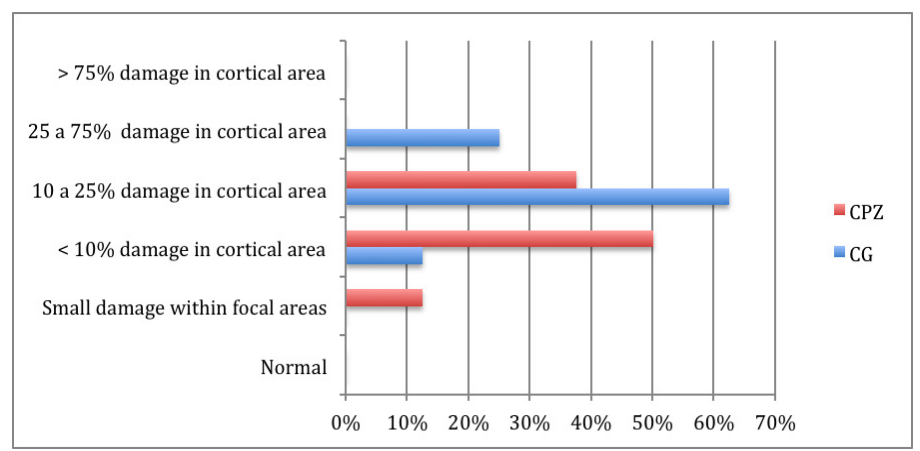

FIGURE 3 - Histological analysis: peritubular capillary congestion in $\mathrm{CG}$ and $\mathrm{CPZ}(\mathrm{p}=0.041)$.
In Figure 4, chlorpromazine administration previous to renal ischemia induction is shown to completely reduce leukocyte accrual in vasa recta.

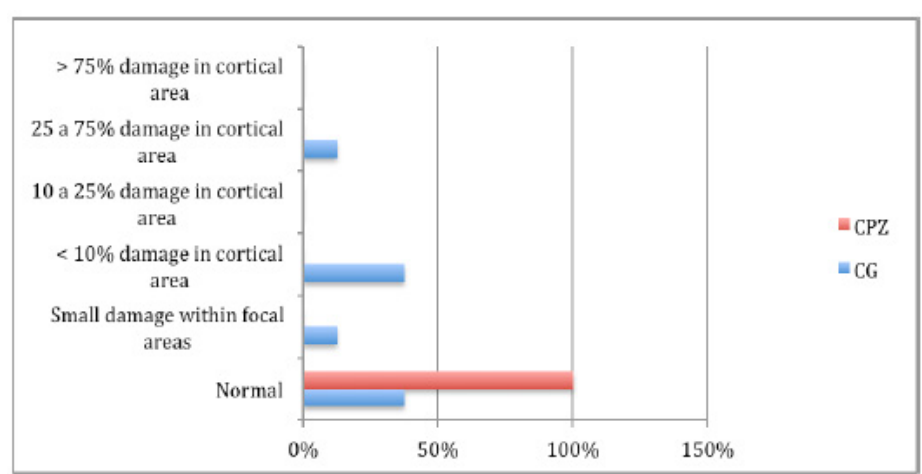

FIGURE 4 - Histological analysis: leukocyte accrual in vasa recta in CG and $\mathrm{CPZ}$ groups $(\mathrm{p}=0.036)$.

Peritubular capillary congestion and leukocyte infiltration in vasa recta renis (Figure 5).
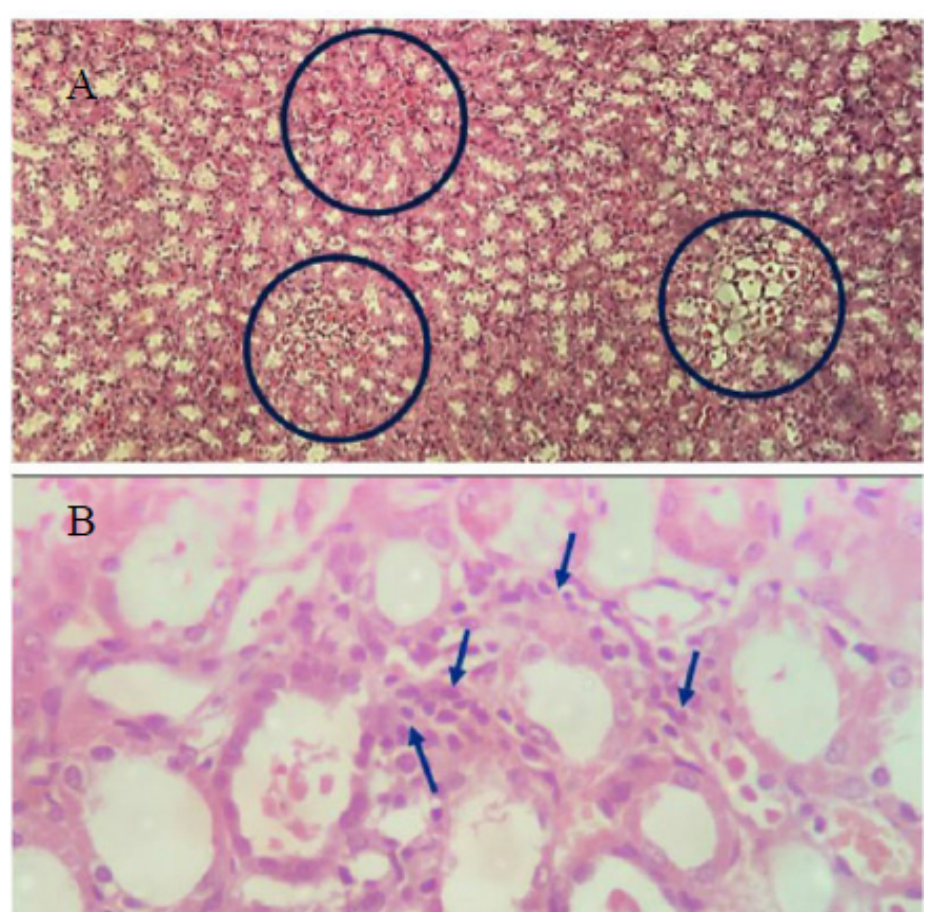

FIGURE 5 - Left kidney slide photomicrograph, 24 hours after ischemia and reperfusion, showing peritubular capillary congestion (A) and leukocyte accrual in vasa recta (B). H\&E staining, x200 zoom.

Figure 6 shows the median scores, first and third quartile of the overall analysis of the histological patterns concerning to ischemia. 


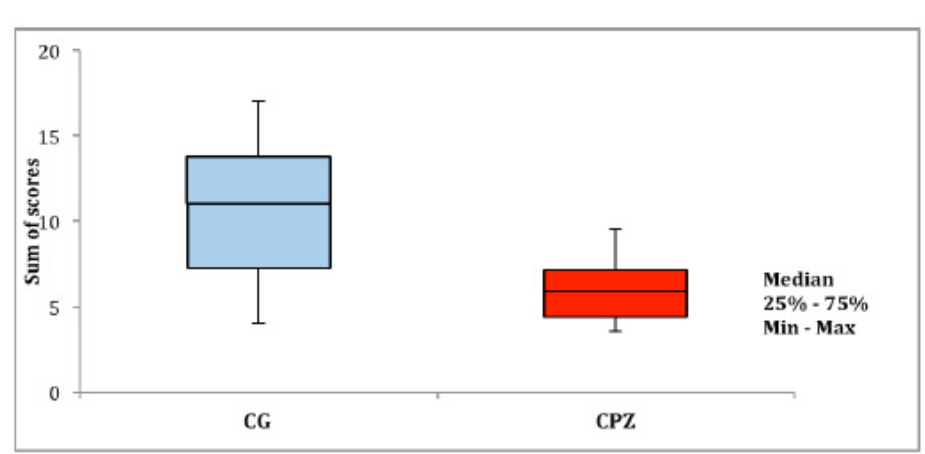

FIGURE 6 - Box- plot showing the median scores, first and third quartiles of histological injury determined by ischemia in groups control (CG) and chlorpromazine $(\mathrm{CPZ})(\mathrm{p}=0.036)$.

\section{Discussion}

Diagnostic equipment technologic development has been providing new findings of ever smaller renal tumors in young individuals, therefore making way to needs of nephron sparing during surgical procedures towards removing such tumors; and partial nephrectomy relates to renal ischemia in order to allow nodule or renal mass removals; and, in order to prevent acute tubular necrosis, damage reduction due to blockage of renal blood flow - one of its main causes - must be attempted ${ }^{2,3}$.

Ischemia already is per se, rather damaging - however, ischemic tissue perfusion may lead to a whole series of problems, increasing tissue lesions, and, when related to systemic complications, it may develop in life-threatening situations for the patient. Oxygen reaction after perfusion leads to tissue damage and starts chain reactions of harmful cell responses previous to inflammation, cell death, and, at last, organ insufficiency ${ }^{11}$.

Usage of nephroprotective drugs minimizes renal ischemia damage; and, chlorpromazine does leave this clinical potential. This benefit can be caused by the generalized vasodilation with improved blood flow caused by chlorpromazine ${ }^{4}$.

Chlorpromazine has anesthetic properties and sympatholytic effects that lead to inhibition of calcium influx, the inactivation of phospholipase and the inhibition of $\mathrm{Na}^{+}$ $\mathrm{K}^{+}$-ATPase, determining the increase in renal blood flow and restoring urine flow. These actions result in improved cell function after ischemia due to cellular energy metabolism modulation of oxidative stress ${ }^{7,12,13}$.

Its protective action against ischemic lesions only occurs when it is administrated before the moment when there is blood flow interruption to the tissue; chlorpromazine is related to ATP recovery levels, calcium metabolism, and, losses of phospholipids ${ }^{4}$. During ischemia, significant alterations within intracellular calcium levels have not been observed; however, during reperfusion, larges amounts of this ion enter into the cells - which does not occur so intensively in animals previously treated with chlorpromazine ${ }^{7}$.

Studies evaluating the chlorpromazine as a protective agent began in $1966^{7}$ and progressed in the $1970 \mathrm{~s}^{8,9}$ and in the $1980 \mathrm{~s}^{12,14}$. From 2001 onwards, new publications, produced in Brazil, have emerged and they show the beneficial usage of chlorpromazine in renal ischemia episodes induced towards renal transplant ${ }^{13,15,16,18}$. The last publication about chlorpromazine was published in $2010^{18}$, and for this reason new studies are necessary to confirm the benefits of this drug in renal ischemia; it's a cheap and easy-to-use drug.

Araujo's experiment has been used as model for this study; periods of time and medication dosage followed such model: chlorpromazine administration 15 minutes prior to renal blood flow obstruction, 60 minutes warm ischemia, post-24 hours damage evaluation, and, $3 \mathrm{mg} / \mathrm{kg}$ chlorpromazine dosage ${ }^{15}$. Distinctively, however, from the functional evaluation on that study, ischemia damage histological evaluation has been preferred. Reasons for such rely on the fact that the right kidney had been preserved thus interfering on results of serum analysis of creatinine and urea.

Chlorpromazine study findings have been, mainly, functional: scintigraphic changes or creatinine and urea counts ${ }^{15}$. There have also been studies towards lipid peroxidation (malondialdehyde count) ${ }^{16}$; however, such study has alternatively focused on a number of histological items caused by ischemia related to renal architecture and chlorpromazine protective action.

When evaluating ischemia, there is a cell lesion triad related to phospholipid cell membrane, ATP and calcium ${ }^{4}$. When chlorpromazine acts on cell metabolism under ischemia, it manages to reduce sublethal and lethal cell damage for it possesses action mechanisms of action over such triad; which explains the decrease on peritubular capillary congestion and on leukocyte accrual in vasa recta renis.

When stabilizing lipid cell membranes, chlorpromazine encourages a decrease on the concentration of toxic aldehydes within cell environment secondary to lipid peroxidation, decreasing the arachidonic acid cycle. Therefore there is a reduction on the generation of chemotactic factors which might lead to leukocyte accumulation in the ischemic bed. Furthermore, once chlorpromazine decreases $\mathrm{Na}^{+} / \mathrm{K}^{+}$-ATPase activity and blocks the calcium channels, it will incur on lower hydrogen release within the respiratory chain, allowing for intracellular $\mathrm{pH}$ maintenance, and a decrease on aldehyde toxicity ${ }^{17}$.

Yet another advantage of the preservation of $\mathrm{Na}^{+} /$ $\mathrm{K}^{+}$-ATPase, and, of the faster hydrogen ion transfer from the mitochondria through respiratory chain stimulus, is the decrease of intra-renal ischemia caused by tubuloglomerular feedback and by sublethal endothelial lesion ${ }^{1,17}$. Consequently, the peritubular 
capillary congestion, present within all evaluated kidneys, occurred not so intensively in the animals which had received chlorpromazine previous to induced ischemia.

The absence of lethal lesions within this experiment goes accordingly some citations that suggest the possibility that kidneys of rats can support a longer period of ischemia ${ }^{19}$. Shorter periods of time have been chosen due to the fact renal lesion from warm ischemia from periods longer than 60-minutes had been observed during the pilot experiment, and, due to the fact most studies regarding chlorpromazine used this timeframe. Within this pilot experiment, transversal serial sections in rat kidneys have been carried out in progressions of 15, 30, 45 and 60 minutes; and, such material was sent to routine histological processing, evaluating alterations resulting from 60 minutes of renal ischemia.

Some limitation of this study: the short follow-up - the left nephrectomy could be performed in a week or more; the comparison could be done also with the contralateral kidney of the same rat. In the future, its usefulness in kidney surgery should be tested by randomized clinical trials.

\section{Conclusion}

The administration of chlorpromazine 15 minutes before the obstruction of the renal blood flow in rats reduced the incidence of ischemic lesions.

\section{References}

1. Tang IY, Murray PT. Prevention of perioperative acute renal failure: what works? Best Pract Res Clin Anaesthesiol. 2004 Mar;18(1):91111. PMID: 14760876.

2. Kutikov A, Uzzo RG. The R.E.N.A.L nephrometry score: a comprehensive standardized system for quantitating renal tumor size, location and depth. J Urol. 2009;182:844-53. PMID: 19616235.

3. Thompson RH, Frank I, Lohse CM, Saad IR, Fergany A, Novick AC. The impact of ischemia time during open nephron sparing surgery on solitary kidneys: a multi-intitutional study. J Urol. 2007 Feb;177(2):471-6. PMID: 17222613.

4. Chien KR, Abrams J, Pfau RG, Farber JL. Prevention by chlorpromazine of ischemic liver cell death. Am J Pathol. 1977 Sep;88:539-54. PMID: 888908.

5. Remzi M, Javadli E, Ozsoy M. Management of small renal masses: a review. World J Urol. 2010;28:275-81. doi: 10.1007/s00345-0100516-8.

6. Balbi AL, Gabriel DP, Barsante RC, Caramori JT, Martin LC, Barreti P. Mortalidade e prognóstico específico em pacientes com insuficiência renal aguda. Rev Assoc Med Bras. 2005;51(6):318-22. doi: 10.1590/S0104-42302011000200012.

7. Murphy GP, Benson DW, Schirmer HK. Renal Response to chlorpromazine in hemorrhagic hypotension: hemodynamic and metabolic changes and adrenolytic effect in dogs. Ann Surg. 1966 Nov;164:867-76. PMID: 1477111.

8. Bilde T, Dahlager JI. The effect of chlorpromazine pretreatment on the vascular function of kidney damaged by warm ischaemia and cold storage in Collins' solution. Scand J Urol Nephrol. 1980;14(2):201-05. PMID: 7209426.

9. Dahlager JI, Bilde T. Renographic evaluation of kidney preservation with chlorpromazine. J Nucl Med. 1979;20(1):18-25. PMID: 430173.

10. Shih W, Hines WH, Neilson EG. Effects of cyclosporin A on the development of immune-mediated interstitial nephritis. Kidney Int. 1988;33:1113-8. PMID: 3261370.

11. Medeiros PJ, Villarin Neto A, Lima FP, Azevedo IM, Leão LRS, Medeiros AC. Effect of sildenafil in renal ischemia/reperfusion injury in rats. Act Cir Bras. 2010;25(6):490-5. PMID: 21120279.

12. Jayachandran S, Mooppan MM, Chou SY, Kim H. Effects of chlorpromazine on ischemic rat kidney: a functional and ultrastructural study. Urology. 1985 Abr;25(4):386-90. PMID: 3984128

13. Netto JMB, Tucci Jr S, Cologna AJ, Suaid HJ, Martins ACP, Molina CAF, Roselino JES. Clorpromazina e função mitocondrial na isquemia-reperfusão renal. Acta Cir Bras. 2001;16:36-40. doi: 10.1590/S0102-86502001000500012.

14. Jablonski P, Howden B, Leslie E, Rae D, Birrel C, Marshall VC, Tange J. Recovery of renal function after warm ischaemia. The effect of chlorpromazine and phenoxybenzamine. Transplantation. 1983 Jun;35(6):535-9. PMID: 6868121.

15. Araujo WM, Tucci Jr S, Costa RS, Ferreira RA, Pozza ML, Mazzeto SA, Alves P, Cologna AJ, Martins ACP. Animal model of ischemic injury, and chlorpromazina protector effect, evaluate by TC-99MMAG3 dynamic renal scan. Acta Cir Bras. 2002;17(3):15-9. doi: 10.1590/S0102-86502002000900004.

16. Tucci Jr S, Carvalho RM, Celini FM, Cologna AJ, Suaid HJ, Tirapeli LF, Martins ACP. Renal ischemia and reperfusion injury: influence of chorpromazine on renal function and lipid peroxidation. Act Cir Bras. 2008;23 Suppl 1:42-5. doi: 10.1590/S0102-86502008000700008.

17. Ayala A, Muñoz MF, Arguelles S. Lipid peroxidation: production, metabolism, and signaling mechanisms of malondialdehyde and 4-hydroxy-2-nonenal. Oxid Med Cell Longev. 2014(2014):1-31. doi: $10.1155 / 2014 / 360438$.

18. Menezes LB, Fioravanti MC, Brito e Silva MS, Franco LG, Sales TP, Andrascko MM, Veado JCC, Araujo EG. Avaliação dos efeitos da clorpromazina sobre a função renal de cães submetidos à isquemia de reperfusão. Pesq Vet Bras. 2010 Fev;30(2):108-14. doi: 10.1590/ S0100-736X2010000200002.

19. Koletski S. Effects of temporary interruption of the renal ciruculation in rats. Arch Pathol. 1954;58(6):592-603. PMID: 13217575.

\section{Correspondence:}

Nicolau Gregori Czeczko

Departamento de Cirurgia-Faculdade Evangélica do Paraná 80730-000 Curitiba - Paraná Brasil

Tel.: (55 41)3240-5488

ngczeczko@gmail.com

Received: July 25, 2016

Review: Sep 26, 2016

Accepted: Oct 24, 2016

Conflict of interest: none

Financial source: none

${ }^{1}$ Research performed at Medical Research Institute, Faculdade Evangélica do Paraná (FEPAR), Curitiba-PR, Brazil. Part of Master degree thesis, Postgraduate Program in Surgery Principles. Tutor: Prof. Dr. Nicolau Gregori Czeczko. 